\title{
ISO 20000 for IT
}

\section{DOI 10.1007/s12599-009-0076-x}

\section{The Author}

\author{
Prof. Dr. Georg Disterer \\ Faculty of Economics and \\ Information Systems \\ University of Applied Sciences \\ and Arts of Hannover \\ Ricklinger Stadtweg 120 \\ 30459 Hannover \\ Germany \\ georg.disterer@fh-hannover.de
}

Received: 2009-03-20

Accepted: 2009-07-27

Accepted after two revisions

by Prof. Dr. Sinz.

This article is also available in German in print and via http://www. wirtschaftsinformatik.de: Disterer G (2009) Zertifizierung der IT nach ISO 2000. WIRTSCHAFTSINFORMATIK. doi: 10.1007/11576-009-0198-2.

\section{ISO 20000 as an instrument for the industrialization of IT}

Since the end of 2005 the international standard ISO 20000 has been deployed for IT service management (ITSM) as a standard for the provision of IT services. Meanwhile, a growing number of IT service providers undergoes ISO 20000 certification in order to provide evidence for their conformity with the standard and to keep it as a quality signal for their customers.

The reason can be seen in the increasing importance of using information technology (IT) to support business processes and transactions in many companies. IT departments no longer take a monopoly position for the provision of IT services per se, but the relations between functional and IT departments are considered as customer/supplier relationships (also) subject to market and competition mechanisms. As a result, both IT departments and IT providers increasingly have to act in a cost- and performance-oriented way. IT service management, i. e. planning, governance and control of the IT service provision, is therefore aimed at implementing major principles and methods from industrial production, a fact known under the slogan of "IT industrialization" (Hochstein and Brenner 2006, p. 4; Walter et al. 2007, p. 6).

\section{Objectives and instruments of a certification according to ISO 20000}

\subsection{Trade-off between quality and cost}

In many companies, success cannot be achieved without high-quality IT services to support business processes. With higher competition and cost pressure the conflict between the objectives "IT quality" and "IT costs" necessarily gains greater attention. Correspondingly, well-known principles and methods from industrial production are used to reach quality and cost objectives. Standardization particularly constitutes an essential driver of IT industrialization. In the field of hardware as well as system and application software comprehensive standardization has already been carried out during the last decades. Now, significant quality and cost improvements are expected from higher standardization of IT service design and operation.

\subsection{Main instruments according to ISO 20000}

The ISO 20000 standard follows the demand to transfer standardization as a principle of industrial production to the provision of IT services. Besides, quality management approaches similar to the ISO 9000 standard are pursued. By means of a targeted and systematic use of a set of instruments, the needs, requirements and expectations of customers with regard to quality and cost of IT services should be met. The main instruments are:

- Standardization: The unification of all practices ensures that operations during IT service provisioning are carried out independently of the people involved, time and place of production. In this way, planning, governance and control of IT services are strongly supported. This also allows for a systematic handling of technical changes as they appear frequently within IT. Standardized procedures can be presented in a transparent way and can be easily communicated. Thus they are understandable, predictable and reliable. Standardization is also a prerequisite for internal or external comparisons of quality and costs of different IT providers as well as for verification and assessment of procedures by independent third parties e. g. in conjunction with a certification.

- Customer focus: Instead of setting a focus (too) strongly on technical conditions, IT services should be provided in a customer-oriented way. Therefore the customers of IT services have to be identified and their needs for information provision and processing have to be analyzed. IT providers and their customers have to clearly agree upon the service offer and have to specify its extent and quality in service level agreements (SLAs). This specification improves transparency of the service offer as well as performance management and monitoring and also supports a performance-oriented way of charging.

- Process orientation: A process-oriented adjustment of IT service creation is meant to avoid disruptions and reduce frictions. In doing so, IT transformation processes follow the prevailing paradigm of process orientation in order to secure continuous processes despite vertical division of labor which is anchored in the organizational structure.

- Continuous improvement: Following the principles of quality management the provisioning of IT services is subjected to continuous verification and assessment in order to persistently and sustainably reduce disruptions and frictions as well as to identify measures for saving resources.

- Alignment to well-known approaches: The standardization of processes can 


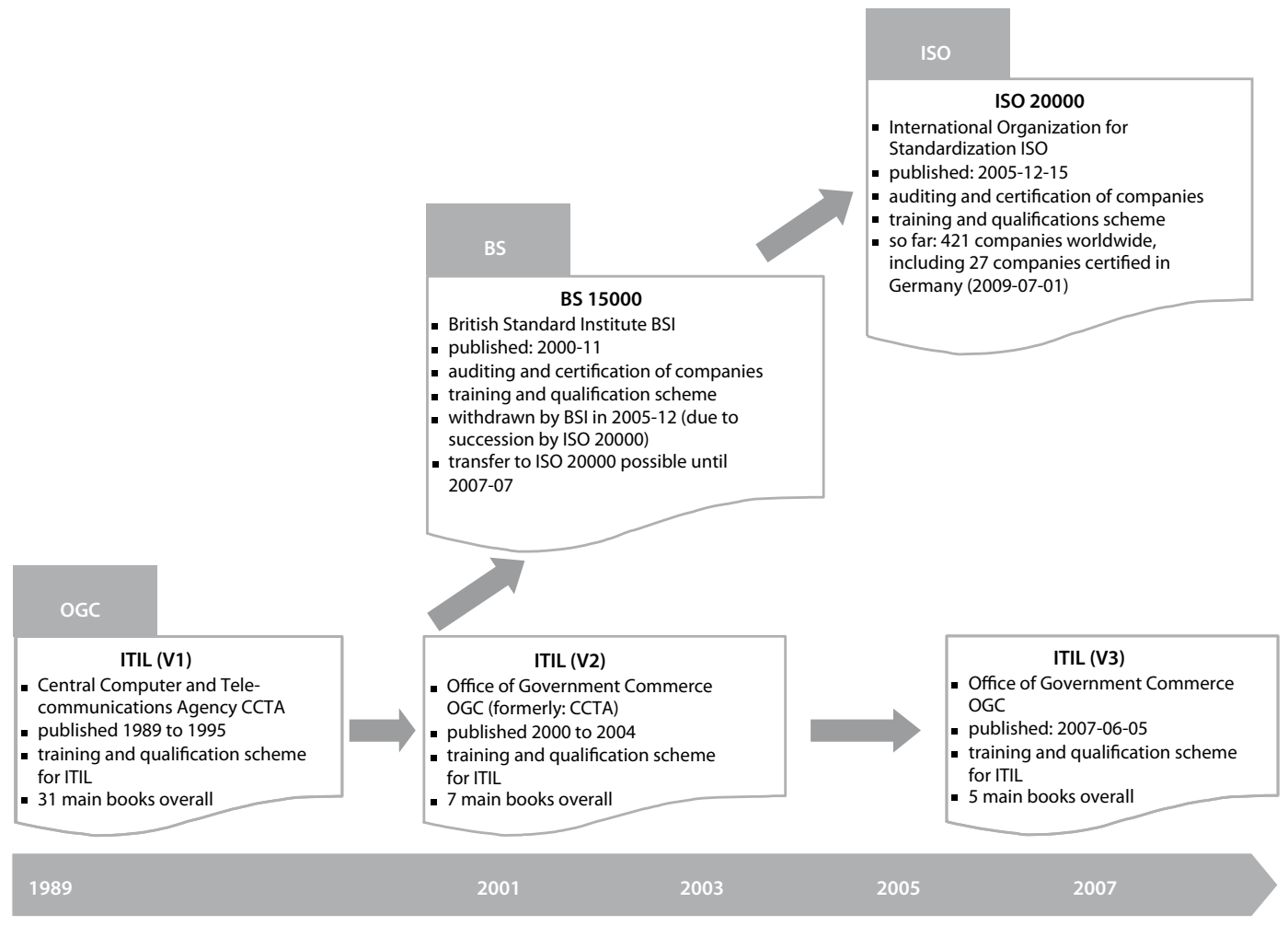

Fig. 1 Origin and development of the ISO 20000 standard be supported by referring to existing frameworks, recommendations, etc. Thus, companies can benefit from developments in science and practice by using "common practices" or "best practices". Despite significant customizations, which are usually necessary to consider company specifics, the use of existing frameworks also supports cost targets as companies do not have to "reinvent the wheel".

- Certification of organization and people: A certificate issued by an independent body serves as a quality seal for fulfilling the conditions and requirements of an approved standard. Regular recertification shows that the compliance with the standard is continuously met over a longer period.

\subsection{Certification impacts}

The certification process has different internal and external effects. For the senior management certification can serve as a relatively clear-cut objective of a complex transformation process. The success can be directly and precisely observed at the end of the process by means of the attained certificate. As a result the transformation process will more likely obtain sufficient attention, priority and resources. For the professionals involved, the objective of certification serves as an impulse, motivation and reinforcement by highlighting the achievement of the certificate at the end of the transformation process. Pursuing certification also intensifies the anchoring of continuous improvement processes for IT services within the organization.

From an external perspective, the certificate serves as seal by an independent body providing customers with evidence that all the conditions and requirements of a recognized standard are met. This evidence can be used as a quality signal to increase an IT service provider's competitiveness if customers tend to choose IT providers based on their compliance with the standard, as is often the case in public tenders and increasingly the case in private practices. The certificate can be used for marketing the IT services since a proof of conformity with approved standards signals trustworthiness and reliability.

The personnel training and qualification scheme contributes to systematic training and to the verification of suitable qualifications of employees for taking on important ITSM tasks.

\section{Origin and evolution of the ISO 20000 standard}

The ISO 20000 standard is based on the "Information Technology Infrastructure Library" (ITIL) reference model and the British standard BS 15000 (Fig. 1).

Since the end of the 1980s, ITIL has been developed by the British authority "Central Computer and Telecommunications Agency (CCTA)", today called Office of Government Commerce (OGC), and is currently available in version 3 (since May 2007). The aim is to provide a reference or framework according to which IT services are to be provided in a process-oriented and systematic way.

ITIL contains a collection of "common practices", i. e. a collection of procedures and practices that have proved successful in practice. The ITIL documentation contains detailed descriptions of essential IT service provisioning processes as well as checklists for the tasks and responsibilities. ITIL is currently considered as a de facto standard for the alignment of all ITSM functions. However, there is no international legitimacy and official recognition.

In 2000, the British Standard BS 15000 was introduced as a quality management system for the provisioning of IT services by the national standardization authority 


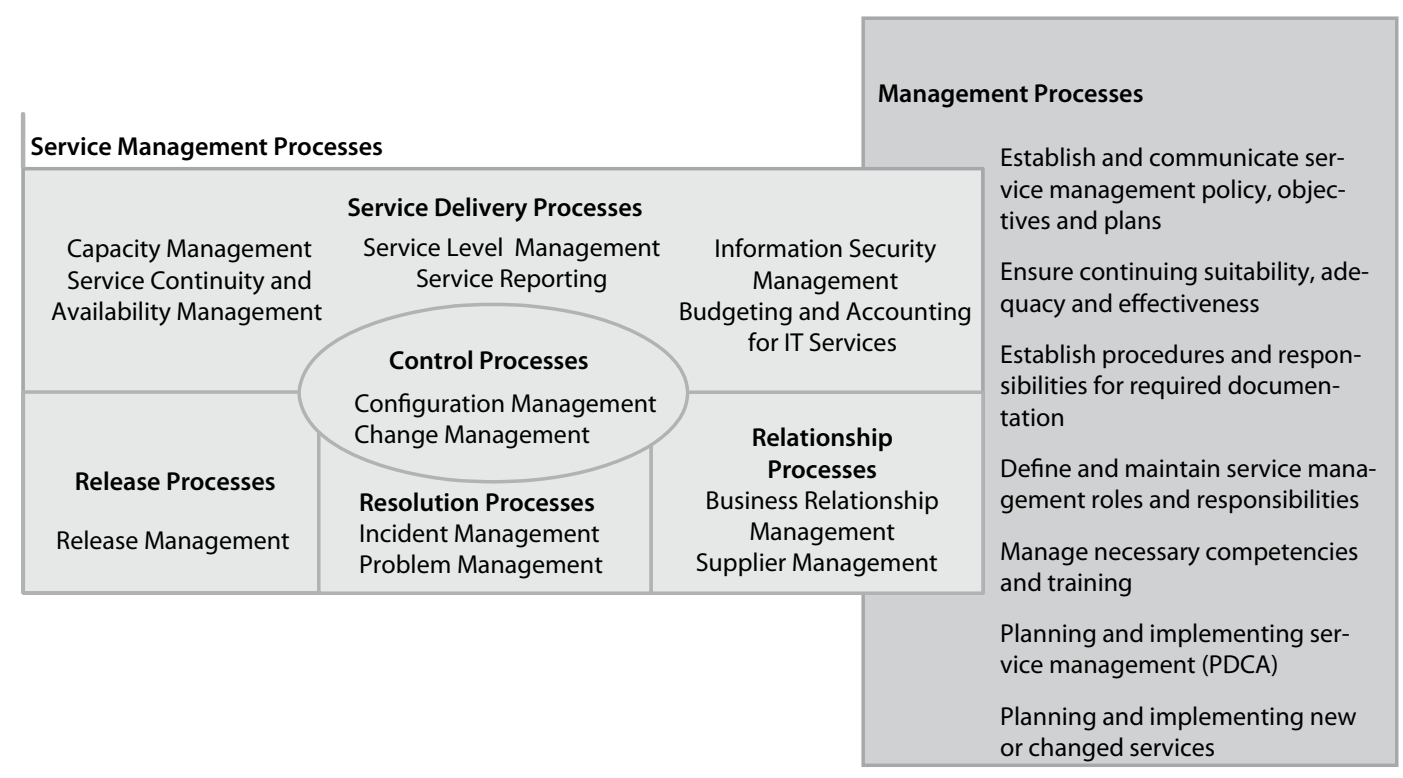

Fig. 2 Service management processes (ISO 20000-1 2005, p. 1)

British Standards Institution (BSI). Many authors of ITIL participated in the development of the standard so that there are strong overlaps of content between ITIL and BS 15000 and only minor differences. Based on BS 15000, companies could receive a certification for complying with the standard's specifications and guidelines. The British standard also gained great international response. Thus, the BSI initiated an authentication process of BSI 15000 as international standard in 2004. Ultimately, the ISO issued the ISO 20000 standard on 2005-12-15 and the BSI consequently withdrew the BSI 15000 standard. ISO 20000 provides a globally acknowledged standard for ITSM allowing for certification of the companies' compliance.

\section{Contents of the ISO 20000 standard}

The standard is codified in the two documents ISO 20000-1 (2005) and ISO 20000-2 (2005). The first document contains the formal specification of the standard and describes the requirements necessary to comply with in order to attain the certificate. Therefore, this part of the standard is referred to as "mandatory criteria" (Buchsein et al. 2007, p. 52; Greb et al. 2006, p. 10) or "minimum requirements" (Buchsein et al. 2007, p. 51; KBSt 2006, p. 8). The second document supplements and clarifies the requirements and provides recommendations for implementation. BSI published supplementing information to these official documents under the heading "Business Information Publications" (BIP), a general introduction to service management (Dugmore and Shirley 2006) and a checklist for verification of conformity with the standard (MacFarlane and Dugmore 2006).

For service management, ISO 20000 prescribes a number of superordinate management processes as well as core service management processes in five process areas (Fig. 2).

The superordinate management processes are supposed to secure a strategic alignment of IT services, in particular an alignment to the objectives of (internal and external) customers as well as economic and quality objectives. For this aim, a service catalogue as a key instrument has to be created and maintained describing all services in detail (including inputs/outputs, quality characteristics, performance parameters, billing procedures,...).

A detailed documentation of responsibilities as well as tasks and procedures has to be set up and maintained in order to provide a transparent service provisioning process and to delineate areas of responsibility. In the sense of a systematic quality management a continuous improvement of processes must be established. In doing so, the standard directly refers (ISO 20000-1 2005, p. 4) to Deming's "Plan-Do-CheckAct" Cycle (PDCA-Cycle) which is wellknown from classical quality management and which highlights the necessity of an integration of planning and ongoing verification of the plans' implementation. Then, with given values for metrics and performance parameters (plan), the ongoing execution (do) of the processes has to be continuously monitored (check) and, if necessary, measures for improvement (act) have to be identified, prioritized, implemented and monitored.

For service management, the standard requires 14 processes in five process areas (Fig. 2), which are strongly based on the ITIL processes (V2). Additionally, the documentation on ITIL (V3) may provide further information and assistance.

\section{Certification process according to ISO 20000}

Companies are awarded certificates according to ISO 20000 upon request and after examination by registered certification bodies (RCB). Fig. 3 illustrates the main stages and tasks of such a certification project.

The total duration of a certification process depends on the company's size and complexity and the extent to which IT service provisioning is already carried out in a process-oriented way. If an alignment with ITIL already exists, an audit can be prepared within 6 to 9 months so that the total time until the final certification may be around 9 to 12 months. If a process orientation according to ITIL (Disterer 2008, p. 1320) or similar references have to be introduced during the certification project the period may amount to up to 3 years.

During the initiation phase, basically the objectives of the certification have to be clarified. What kinds of benefits are expected and which resources (time, personnel, finance) are needed - according to 

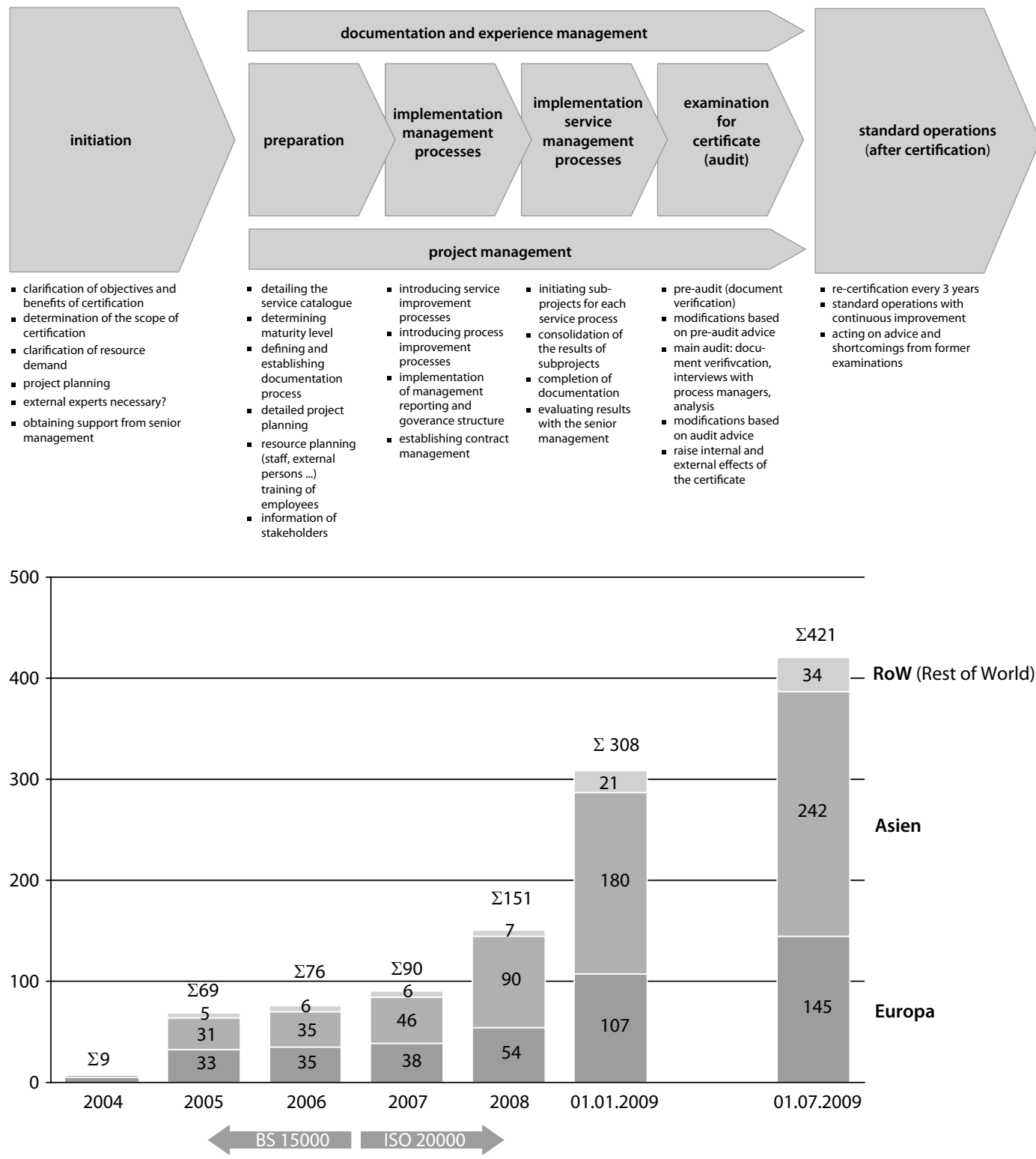

Fig. 3 Certification project according to ISO 20000
Fig. 4 Number of certified companies (Source: ITSMF 2009) initial estimates? During the preparatory phase it has to be determined which of the necessary superior management and service management processes are already in place and to what degree they comply with the standard. This requires the development or completion of the service catalogue as well as the identification of all major components of the services and the disclosure of relationships and dependencies. The value chain of suppliers via the internal service provision to the customers has to be incorporated. It is necessary to ascertain which level of "maturity" for IT service provision already exists and to what extent this maturity level is sufficient for certification. Checklists (e. g. ITSMF n. d.) are used for recognizing necessary changes in order to meet the minimum requirements of the standard.
An important part of the certification examination refers to the documentation of processes. Therefore, the documentation has to be defined and agreed on at an early stage, using guidelines for document storage, document sharing, naming conventions, version control, and change history.

During the implementation of management processes an overall governance and control system has to be determined and introduced. This system must be aligned to the requirements of the continuous improvement in the "Plan-Do-CheckAct" cycle. In particular, it is important to establish how service improvements and processes improvements are to be conducted. To implement the service management processes, the definition of subprojects will be necessary since the available personnel resources usually do not allow all processes to be introduced simultaneously.

In the first part, the examination for certification (audit) consists of a visual inspection of all documents (reports, process descriptions, figures...), which are to be sent to the certification authority. This investigation serves to prepare the certification body for the main examination. Later on, the certification authority's representatives conduct the second part of the examination as an on-site inspection lasting several days. This includes interviews with all responsible persons in which they describe the processes, explain details and specifics, define process documentations, justify ratios and performance parameters and their development as well as comment on identified weaknesses and initi- 


\begin{tabular}{l}
\hline Tab. 1 Currently certified compa- \\
nies in Germany, as of 2009-07-01 \\
(ITSMMF 2009) \\
\hline BadenIT \\
\hline BT (Germany) \\
\hline Capgemini Outsourcing Services \\
\hline Computacenter \\
\hline CSC \\
\hline European Central Bank \\
\hline FIDUCIA IT \\
\hline Fujitsu Siemens Computers \\
Infrastructure Services \\
\hline GEFA Gesellschaft für Absatzfinanzierung \\
\hline GRASS-MERKUR \\
\hline Interhyp \\
\hline Munich Airport \\
\hline OneVision Software \\
\hline ORGA \\
\hline PC Service \\
\hline Prosystems IT \\
\hline Regio IT Ges. für Informationstechnologie \\
\hline SAP Hosting \\
\hline Siemens IT Operations \\
\hline Siemens IT Solutions and Services \\
\hline Siemens Medical Solution \\
\hline Telefonica Deutschland \\
\hline Toll Collect \\
\hline T-Systems Enterprise Services \\
\hline T-Systems Solutions for Research \\
\hline Vattenfall Europe Information Services \\
\hline
\end{tabular}

ated improvement actions (for exemplary test questions see Bock et al. 2006, p. 253265).

Finally, the certification authority provides a report analyzing the audit results and explaining measures for possible improvement to be implemented before the next examination. In case of a positive overall result the company receives an official certificate confirming conformity of IT service provision with the requirements of ISO 20000.

The phase of standard operation begins after the certificate, which is valid for 3 years, has been issued. After expiration a recertification can be carried out, which is principally done by the same procedure as described above, but usually requires less effort.

\section{Dissemination: The state of cer- tification according to ISO 20000}

So far, 421 companies have been certified according to ISO 20000 (Fig. 4). As regards Europe, relatively many companies are based in the UK (54), which can partly be explained by the fact that a British predecessor existed with the national standard BS 15000, from which companies could switch to ISO 20000 in a simplified transition process until mid 2007.

The comparatively small number of 20 certified companies in the USA confirms the currently prevailing assumption that standards such as ISO 20000 and reference models such as ITIL (still) do not receive great attention in the USA; verified investigations, however, are not available. The large number of certificates in Asia can be explained by the fact that many of these IT vendors offer their services in offshoring transactions to companies in Western Europe and North America and intend to signal trustworthiness and reputation by means of the certificate. In Germany, currently 27 companies are certified, which are listed in Tab. 1.

\section{Outlook}

The number of companies certified according to ISO 20000 is expected to increase in the coming years. This will mainly result from increasing customer pressure calling for an evidence of compliance with minimum requirements of IT services. The relevant literature cites predictions according to which future procurement projects in both public and private companies increasingly and explicitly require certification under the terms of ISO 20000 (Gartner Group, according to Buchsein et al. 2007, p. 51). In addition, IT providers will more and more try to achieve competitive advantages by using the certificate as a quality signal for indicating trustworthiness and reputation.

\section{References}

Bock W, Macek G, Oberndorfer T, Pumsenberger $\mathrm{R}$ (2006) ITIL Zertifizierung nach BS 15000 / ISO 20000. Galileo, Bonn

Buchsein R, Victor F, Günther H, Machmeier V (2007) IT-Management mit ITIL V3. Vieweg, Wiesbaden
Disterer G (2008) ITIL als Referenzmodell für das IT Service Management. Das Wirtschaftsstudium WISU 37:1320-1329

Dugmore J, Shirley L (2006) A managers' guide to service management (BIP 0005), 5th edn. British Standards Institution, London

Greb T, Kneuper R, Stender J (2006) Nutzung der CMMI-Assessmentmethode für ITIL-Prozesse. IT Service Management 1(3): 10-15

Hochstein A, Brenner W (2006) Grundlagen des IT Service Management. IT Service Management $1(1): 3-7$

ITSMF (2009) http://www.isoiec20000 certification.com. Accessed 2009-07-01

ITSMF (nd) http://www.itsmf.com. Accessed 2009-01-07

ISO 20000-1 (2005) Information technology Service management - Part 1: Specification ISO 20000-2 (2005) Information technology Service management - Part 2: Code of practice KBSt Koordinierungs- und Beratungsstelle der Bundesregierung für Informationstechnik in der Bundesverwaltung (2006) ITIL und Standards für IT-Prozesse (V 1.0.1). Bundesministerium des Innern, Berlin

MacFarlane I, Dugmore J (2006) IT service management - Self-assessment workbook (BIP 0015), 3rd edn. British Standards Institution, London

Walter S, Böhmann T, Krcmar H (2007) Industrialisierung der IT - Grundlagen, Merkmale und Ausprägungen eines Trends. Handbuch der modernen Datenverarbeitung 256:6-16 